\title{
Management of men with ultra-short penile urethral stricture using augmented anastomotic penile skin flap urethroplasty; a retrospective analysis
}

\author{
Abdel W. El-Kassaby ${ }^{1}$, Mohammed Saber Khalaf $2^{2^{*}}$ and Ahmed M. Reyad² ${ }^{2}$
}

\begin{abstract}
Background: The management of short anterior urethral stricture is challenging. Our study aims to evaluate the outcome of augmented anastomotic urethroplasty (AAU) for the management of men with ultra-short penile urethral stricture, and to compare it with the dorsal onlay buccal mucosa graft.

Methods: Databases of two tertiary referral centres were retrospectively reviewed to retrieve data of men with ultrashort penile urethral stricture who underwent urethroplasty from 2013 to 2020. Patients who underwent AAU with ventral onlay pedicled skin flap were considered the study group, while patients treated with the dorsal onlay graft augmentation were included as controls. Surgical outcomes included urethral patency, improvement in the maximum flow rate (Qmax), change in sexual satisfaction, and any reported complications.

Results: Thirty-four patients (and 30 controls) with a median age of 26-27 years were included in the study. The maximum flow rate improved significantly in both groups compared to the preoperative value $(p<0.001)$. The success rate was $88 \%$ in the study group compared to $76.7 \%$ in the control group. There was no statistically significant difference in the frequency of postoperative penile curvature nor the ventral sacculation between the two groups $(p=0.788$ and 0.913$)$. The operative time was statistically significantly longer in the control group $(p=0.044)$, while the frequency of postoperative void dripping was much higher in the study group ( $p=0.007$ ).
\end{abstract}

Conclusion: The success rate and complications of AAU for men with ultra-short penile urethral stricture were comparable to the dorsal buccal graft.

Keywords: Augmented anastomotic urethroplasty, Dorsal strip, Penile urethral stricture, Orandi flap

\section{Background}

Anterior urethral stricture is a common urologic disorder prevalent in men. It is associated with a significant deterioration in the quality of life and elevation in healthrelated expenditures [1]. It is reported that untreated urethral strictures may lead to acute retention and prostatitis in more than $50 \%$ of patients [2]. After bulbar urethra,

\footnotetext{
*Correspondence: mohammed_uro90@yahoo.com

2 Department of Urology, Sohag University Hospital, Sohag, Egypt Full list of author information is available at the end of the article
}

the penile urethra is the second-most commonly affected site by strictures (30\%) [3]. The most commonly reported cause of penile urethral strictures is iatrogenic [4]. However, the strictures may result from traumatic avulsion of the penile urethra in association with a fractured penis, in which sexual trauma is one of the main etiological factors [5].

The current literature describes several surgical procedures to correct penile urethral stricture. However, the choice of optimal treatment is primarily driven by stricture etiology, length, and lumen conditions $[6,7]$. The 
repair of penile stricture can be done in one-stage or twostage urethroplasty. Two-stage urethroplasty is required for more complex penile urethral strictures caused by lichen sclerosis (LS) or failed hypospadias repair. On the other hand, Dorsal Inlay (Asopa technique) or dorsal onlay graft (Barbagli technique) are the most common procedures used for one-stage repair; however, these techniques are not suitable for stricture diameter less than $6 \mathrm{~mm}$. Besides, circumferential mobilization of the urethra in the Barbagli procedure may compromise the urethral blood supply $[8,9]$.

The length of the penile urethral stricture is usually long. Thus, data are scarce regarding the short penile stricture less than $1 \mathrm{~cm}$ in length. Despite the high success rate of excision and primary anastomosis in the management of short bulbar urethral stricture, its use in the penile urethra is limited due to the risk of penile chordee [10,11]. Augmented anastomotic urethroplasty (AAU) is an alternative technique for the management of long bulbar urethral strictures with an extended area of narrowing and fibrosis [12]. Moreover, the technique combines the advantages of both anastomosis and graft substitution [13]. Up to our knowledge, no previous studies used this technique for the management of penile urethral stricture. The aim of our study is to investigate the outcome of AAU for the management of ultra-short penile urethral stricture $(<1 \mathrm{~cm})$ and to compare this technique with the dorsal buccal mucosa only graft.

\section{Methods}

This study is a retrospective analysis of the records of patients with penile urethral stricture who underwent urethroplasty between January 2013 and January 2020 at two tertiary centers. The study was approved by the Local Ethical Committee of the two tertiary centers. The current study included men with penile urethral stricture $(\leq 1 \mathrm{~cm})$ [ultra-short penile urethral stricture] who underwent either AAU using ventral onlay pedicled skin [Orandi] flap procedure (study group) or dorsal Buccal mucosa onlay graft augmentation (control group).

Exclusion criteria included patients with a previous history of a visual internal urethrotomy, previous urethroplasty, genital skin diseases (lichen sclerosis), or patients with missed or incomplete data. The study was approved by the ethics committee of Sohag University, Faculty of medicine with approval number REC/09/012,020.

Preoperatively, patients were evaluated by history and local examination. Urethral patency was assessed using retrograde and voiding urethrogram (Fig. 1), followed by sonourethrography to identify and assess the degree of any periurethral fibrosis. The sexual function was evaluated using the Sexual Health Inventory for Men (SHIM) questionnaire [14]. The maximum flow rate (Q-max) was assessed by uroflowmetry. The retrieved Patients' data included stricture length, site, and etiology.

\subsection{Augmented anastomotic urethroplasty technique}

After the induction of spinal anesthesia, the patients' positions were adjusted to the standard supine position. The procedure was started by applying a stay suture through the glans penis with 4.0 vicryl suture to stretch the penis and urethra. The distal end of the penile stricture was identified using a Nelaton catheter $20 \mathrm{~F}$ that was passed through the meatus, followed by injection of methylene blue. At the tip of the Nelaton catheter, a ventral longitudinal skin incision was performed till the

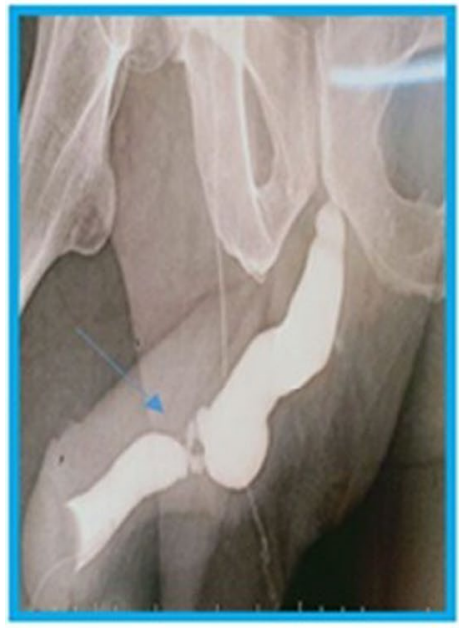

a

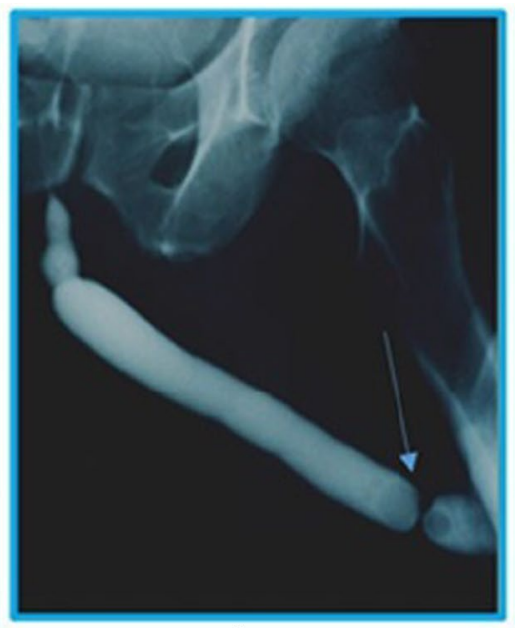

b

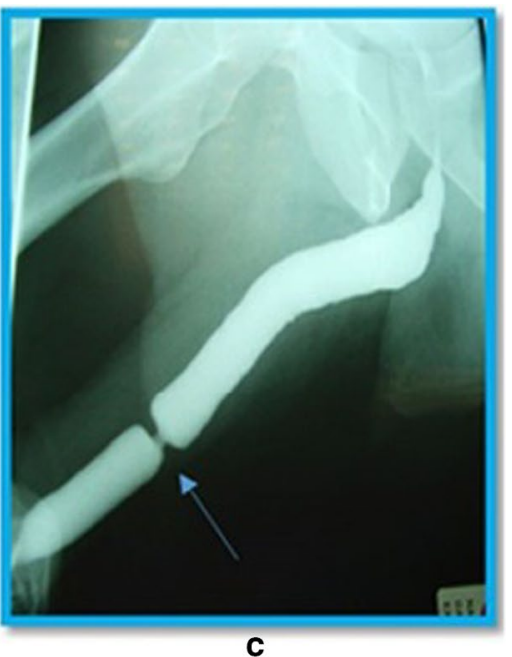

Fig. 1 Preoperative retrograde urethrogram showing ultra-short penile urethral stricture 
distal end of the stricture. Next, ventral stricturotomy was performed until the healthy urethra was reached proximally over a guidewire or 4 French ureteric stents. The stricture segment was evaluated for residual lumen and its length. Limited circumferential urethral mobilization was performed allowing for tension-free anastomosis of dorsal urethral ends. The ventral defect is augmented using longitudinal non-hairy ventral skin flap that was designed and mobilized as an Orandi flap, corresponding to the length of the ventral urethral defect [15]. The flap was sutured in a ventral onlay fashion using 5.0 vicryl in two layers using the flap pedicle and adjacent tissue as a $2^{\text {nd }}$ layer. The repair was performed over a silicon catheter $18 \mathrm{~F}$. The wound was closed in layers without drain, followed by a dressing of the penis with compressive dressing [Fig. 2].

\subsection{Dorsal Onlay graft augmentation technique}

A subcoronal circumcision incision was made, and complete degloving of the penile skin was done. The distal end of the penile stricture was identified using a Nelaton catheter $20 \mathrm{~F}$ that was passed through the meatus, followed by injection of methylene blue. The urethra was circumferentially dissected from the corpora cavernosa. The urethra is rotated $180^{\circ}$, the dorsal urethral surface was exposed and fully opened. The stricture was then opened for its entire length by extending the urethrotomy into the healthy urethra $1 \mathrm{~cm}$ distally and proximally. Once the entire stricture has been incised, the length and width of the remaining urethral plate were measured. The oral mucosal graft was harvested from the inner cheek by another team and fixed over tunica of the corporal bodies using 5/0 vicryl sutures. A $16 \mathrm{Fr}$ silicon catheter was inserted. Interrupted $5-0$ polyglactin sutures were used to stabilize the urethral margins onto the corpora cavernosa over the graft at each side. At the end of the procedure, the graft was completely covered by the urethra; then, the classic closure of the skin and underlying dartous was performed over an $18 \mathrm{Fr}$ silicon catheter [16].

\subsection{Postoperative assessment}

All patients were discharged home after $48 \mathrm{~h}$. The urethral catheters left for 3 weeks and were removed after peri-catheter retrograde urethrogram. In the case of extravasation, the catheter was left for one more week. The suprapubic catheters were left in place for few days after urethral catheters to ensure a satisfactory voiding before removal. Voiding cystourethrography was performed at 6 months postoperatively (Fig. 3) while flowmetry was done at 3 and 6 months. Patients were asked to complete the SHIM questionnaire before and 12 months after the surgery. The penile curvature was examined using a goniometer in an artificial erection state and was classified according to Kelami classification [17]. Patients were then interviewed by telephone annually to rule out any change in their LUTS.

The primary outcome was the overall success rate, which was defined according to the urethral patency and the improvement in the maximum flow rate (Qmax). Failure of the procedure was defined as any postoperative urethral intervention or instrumentation. The secondary outcome was the occurrence of complications as a decline in SHIM score and any recorded penile curvature.

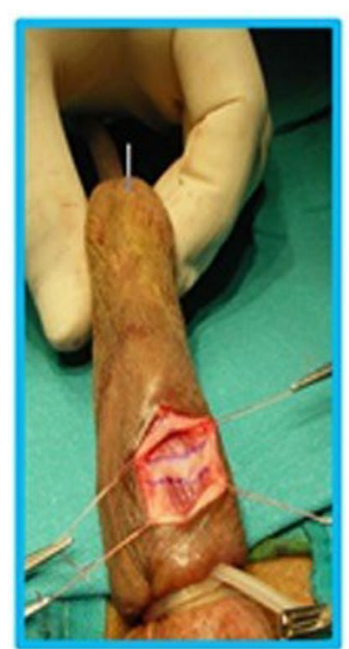

a

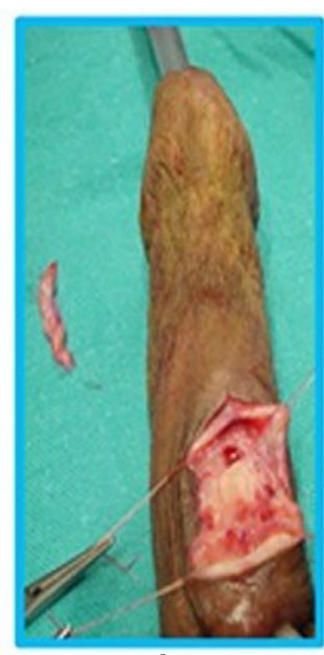

b

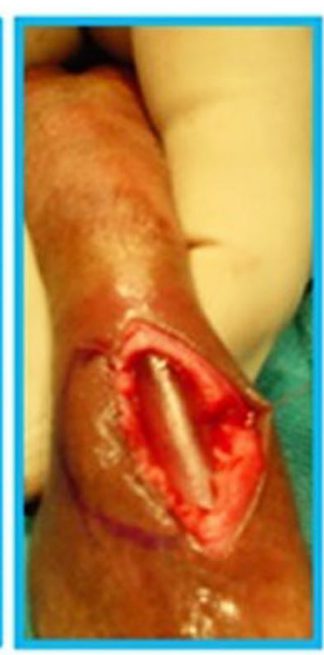

C
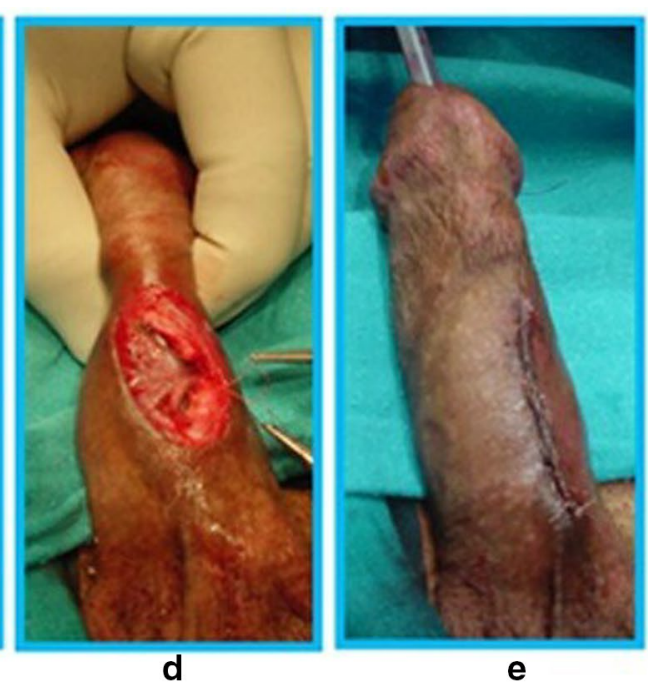

Fig. 2 a Ventral stricturotomy and marking the fibrotic segment, $\mathbf{b}$ excision of fibrotic urethral segment, $\mathbf{c}$ Dorsal strip anastomosis of penile urethra and fashioning of Orandi flap; $\mathbf{d}$ ventral onlay anastomosis of Orandi flap; e wound closure 


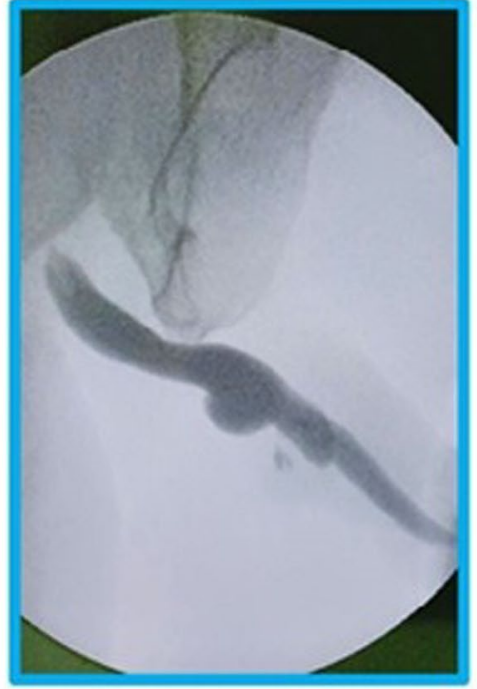

a

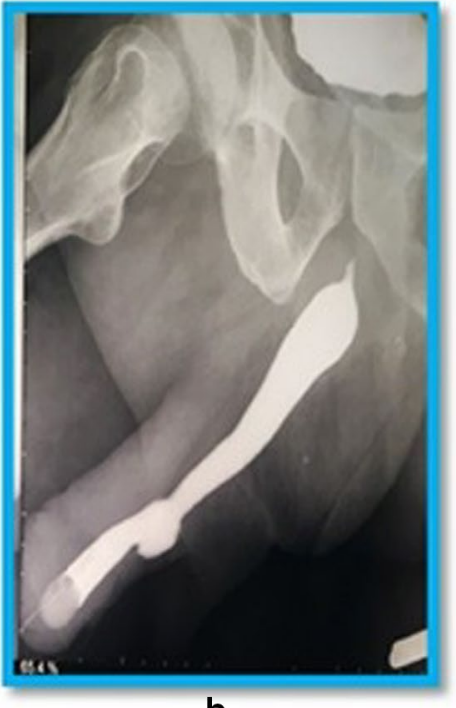

b

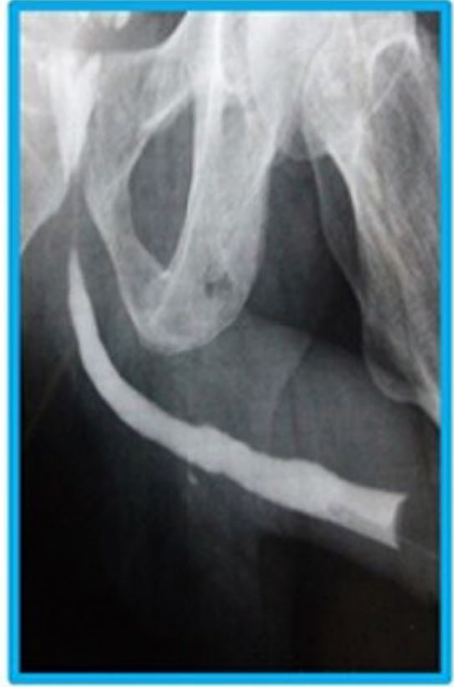

C

Fig. 3 Postoperative retrograde urethrogram

\subsection{Statistical analysis}

The statistical analysis was performed using the SPSS software (Statistical Package for the Social Sciences, version 24, SSPS Inc., Chicago, IL, USA). Frequency tables with percentages were used for categorical variables, and descriptive statistics (mean and standard deviation) were used for numerical variables. Paired $t$ tests were conducted to detect the significance of the change of flow rate. A $p$ value of less than 0.05 was considered statistically significant.

\section{Results}

In the present study, the records of 78 patients with ultra-short penile urethral stricture were reviewed. A total of 14 patients were excluded due to missed data, previous urethroplasty, and a history of previous visual internal urethrotomy. Thus, 64 patients' records were included in the final analysis; 34 of them had AAU (study group), and 30 patients underwent a dorsal only buccal mucosa graft (control) group. The median (range) of ages in the study groups was 26 years (range 18-34 years), while were 27(18-36 years) for the control groups. There were no statistically significant differences between the two groups in terms of preoperative stricture length, maximum flow rate (Q-max), and the post-void residual urine. The most common cause of stricture was iatrogenic (59.4\%) followed by idiopathic $(29.7 \%)$ in both groups. The most common site of stricture was the mid-penile shaft (Table 1). In the control group, the five patients with distal penile strictures were at the fossa navicularis, while those with proximal penile were bulb-penile strictures. The percutaneous suprapubic catheter was inserted in 22 (64.7\%) patients preoperatively owing to upper tract dilatation and for the eradication of urinary tract infections.

Postoperatively, Q-max improved significantly in both groups compared to the preoperative value $(p<0.001)$. There was no statistically significant difference in the frequency of postoperative penile curvature nor the ventral sacculation between the two groups ( $p=0.788$ and 0.913). Despite the higher frequency of stricture recurrence in the control group, this was not statistically significant $(p=0.322)$. The operative time was statistically significantly longer in the control group $(p=0.044)$, while the frequency of postoperative void dripping was much higher in the study group $(p=0.007)$ (Table 2).

During the median follow-up period 31 (12-50) months, $30(88 \%)$ patients were successful, whereas four $(12 \%)$ patients required interventions in the study group; two patients developed recurrent stricture during the first year, one patient at the second year, and the fourth patients developed urethra-cutaneous fistula at the $3^{\text {rd }}$ month. All failed patients underwent surgical revision within 6 months after their primary urethral repair. Regarding the control group, 23 (76.7\%) patients were successful and 7 (23.3\%) suffered recurrent stricture, and staged urethroplasty was performed for them after 6 months.

No significant difference was found in mean SHIM scores $(22 \pm 1.3$ and $21.7 \pm 0.1$, respectively, $p=0.23)$. 
Table 1 shows the pre- and intraoperative characteristics of the included patients

\begin{tabular}{|c|c|c|c|}
\hline Variable & $\begin{array}{l}\text { Cases } \\
(\mathrm{N}=34)\end{array}$ & $\begin{array}{l}\text { Controls } \\
(\mathrm{N}=30)\end{array}$ & $p$ value \\
\hline Age in years, median (range) & $26(18-34)$ & $27(18-36)$ & $0.322(\mathrm{NS}) \wedge \wedge$ \\
\hline \multicolumn{4}{|l|}{ Site of stricture (\%) } \\
\hline Distal penile & $6(18)$ & $5(17)$ & \multirow[t]{3}{*}{$0.994(N S)^{*}$} \\
\hline Mid-penile & $18(53)$ & $16(53)$ & \\
\hline Proximal penile & $10(29)$ & $9(30)$ & \\
\hline \multicolumn{4}{|l|}{ Cause of stricture (\%) } \\
\hline Traumatic & $3(9)$ & $4(13)$ & \multirow[t]{3}{*}{$0.964(\mathrm{NS})^{* *}$} \\
\hline latrogenic & $20(59)$ & $18(60)$ & \\
\hline Unknown & $11(32)$ & $8(27)$ & \\
\hline Stricture length in $\mathrm{cm}$, mean $( \pm S D)$ & $0.72 \pm 0.21$ & $0.63 \pm 0.24$ & $0.118(\mathrm{NS})^{\wedge}$ \\
\hline Flow rate in $\mathrm{mL} / \mathrm{sec}$, mean $( \pm S D)$ & $3.36 \pm 1.32$ & $3.19 \pm 1.19$ & $0.590(\mathrm{NS})^{\wedge}$ \\
\hline Post-micturition residual, mean ( \pm SD) & $270.2 \pm 20.1$ & $255.9 \pm 35.3$ & $0.055(\mathrm{NS}) \wedge$ \\
\hline
\end{tabular}

* Pearson Chi-square test was used

** Fisher exact test was used instead of Pearson chi-square test

$\wedge$ Student $t$ test was used

$\wedge \wedge$ Mann-Whitney test was used instead of Student $t$ test

Table 2 Shows the postoperative outcomes

\begin{tabular}{|c|c|c|c|}
\hline Variable & $\begin{array}{l}\text { Cases } \\
\mathrm{N}=34 \text { patients }\end{array}$ & $\begin{array}{l}\text { Controls } \\
\mathrm{N}=30 \text { patients }\end{array}$ & $p$ value \\
\hline Operation time (hrs.) mean ( \pm SD) & $1.72 \pm 0.35$ & $2.11 \pm 0.29$ & $0.044(S) \wedge$ \\
\hline Post-void dripping frequency (\%) & $12(35.3)$ & $2(6.6 \%)$ & $0.007(\mathrm{~S})^{\wedge}$ \\
\hline Recurrent stricture, frequency (\%) & $4(12)$ & $7(23)$ & $0.322(\mathrm{NS})^{*}$ \\
\hline Last flow rate in $\mathrm{mL} / \mathrm{sec}$, mean $( \pm \mathrm{SD})$ & $19 \pm 3.4$ & $21 \pm 4.8$ & $0.062(\mathrm{NS}) \wedge$ \\
\hline Penile curvature, frequency (\%), & $3(9)$ & $3(10)$ & $0.788(\mathrm{NS})^{*}$ \\
\hline Ventral sacculation, frequency (\%) & $2(6)$ & $1(3)$ & $0.913(N S)^{*}$ \\
\hline
\end{tabular}

* Fisher exact test was used

$\wedge$ Student $t$ test was used

The overall complication-free and failure-free were $88 \%$ and $70 \%$ after 20 months of follow-up according to the Kaplan-Meier function curve for the studied patients.

\section{Discussion}

In the current retrospective study, both AUU and dorsal buccal mucosa only graft were comparable regarding the postoperative outcomes. The overall incidence of recurrent stricture, penile curvature, and ventral sacculation was low with a statistically insignificant difference between the two groups. However, the operative time was statistically significant longer in dorsal graft compared to AAU, and the frequency of post-void dripping was statistically and clinically higher in the AAU group.

The choice of surgical repair for penile urethral stricture depends on stricture etiology, the extent of spongiofibrosis, and the surgeon experience [18]. The repair of penile urethral stricture is more challenging because of the small thickness of corpus spongiousum and consequently lack of support for ventrally placed grafts. Furthermore, excessive mobilization of penile urethra could compromise the critical blood supply for the circumferential arteries.

For penile urethral strictures, the surgical options for urethral reconstruction include buccal mucosa urethroplasty using dorsal onlay or dorsal inlay techniques, fasciocutaneous local skin flap urethroplasty or staged approach in longer and more complex cases. Excision and primary anastomosis can lead to tension and chordee, whereas the risk of sacculation or pseudo-diverticulum formation increases in cases of ventral onlay with pedicled flaps $[6,10]$.

The causes of penile urethral stricture in our study were iatrogenic trauma in 59\%, Idiopathic in 30\%, and traumatic in $11 \%$. While in developed countries, LS and failed hypospadias repair are reported to be the most common 
causes [19]. This could explain the short stricture length in our patients.

Augmented anastomotic urethroplasty is usually employed for longer unequal bulbar urethral strictures that have a segment with dense spongiofibrosis and too narrow residual lumen not suitable for augmentation urethroplasty. It is a combination repair and comprises excision and substitution urethroplasty [13]. In our study, the success rate of the AAU group was $88 \%$ in terms of anatomical urethral patency. Three patients (9\%) developed mild penile curvature $(<15$ degrees), while two patients $(6 \%)$ developed ventral sacculation.

In 2001, Guralnick and Webster reported a 93\% success rate for AAU as shown in their retrospective analysis at a mean 28-month follow-up. However, in their study, they did not state a clear definition for successful repair as they had one patient that did dilatation and one patient underwent visual urethrotomy. $21 \%$ of patients noticed some degree of penile shortening however they report that they were "neither measured nor problematic [12]. In 2007, a retrospective analysis done was by Abouassaly and Angermeier, where they reported their results with AAU in 69 patients showing a success rate of $90 \%$ in median follow-up period of 34 months. On the other hand, their main complications were UTI and stricture recurrence, with no report of penile curvature. They were using oral mucosa in their surgical repair [13]. In 2008, El-Kassaby and coworkers reported their results in AAU for long bulbar stricture and the overall success rate was 93.7\%. They reported an incidence of $40.4 \%$ of postoperative dribbling of urine which is similar to the current results (41\%). It should be mentioned that they had temporary perioral numbness in most patients [6]. More recently, Hoy and colleagues reported their outcomes in AAU in long bulbar urethral stricture even more than $5 \mathrm{~cm}$. The success rate (no stricture recurrence) was $96.9 \%$, and the main complication was post-void dribbling $(41.7 \%)[20,21]$. The success rate in our study was slightly lower than reported in the literature; however, we should emphasize that all previous studies used AAU for bulbar urethral stricture, which has more limits of mobilization and thick supportive corpus spongiousum. Besides, their sample size was larger.

On the other hand, the success rate of dorsal onlay graft augmentation in our study was $76.7 \%$. The success rate varied widely in the literature. In 1998, the success rate of the dorsal onlay graft urethroplasty using penile skin as a substitute material, with a mean follow-up of 21.5 months, was $92 \%$ [22]. In 2001, the success rate, with a mean follow-up of 43 months, was $85 \%$ [23]. In 2008, the success rate, with a mean follow-up of 111 months, decreased more to $65.8 \%$ [24]. Finally, in 2014, the success rate, with a mean follow-up of 190 months, was
63.6\% [11]. The use of buccal mucosa is superior to the penile skin in dorsal onlay graft bulbar urethroplasty. The success rate of buccal mucosa used in 6 patients, showed a $100 \%$ success rate at 13.5 months mean follow-up [22]. In 2005 , the success rate on 23 cases with 42 months mean follow-up, was 85\% [25]. Notably, the success rate of the dorsal only graft in this study was lower than reported in the literature. This could be explained by the dense fibrosis and the markedly reduced lumen in this group $(<6 \mathrm{~mm})$.

Our results showed that AAU could be a reliable procedure to manage ultra-short penile urethral stricture with an obliterated lumen (residual urethral plate width less than $6 \mathrm{~mm}$ ) that appeared unsuitable for one-stage urethroplasty. The pedicled skin flap was used as a ventral onlay. The pedicled skin flap is a long, hairless, and flexible flap that is suitable for restoring the urethral patency without cosmetic disfigurement. In addition, the operative time of AAU was shorter than of the dorsal onlay buccal mucosa graft. But, the frequency of post-void dripping is high due to the risk of ballooning of the ventral flap caused by the lack of ventral support. This finding was in tandem with other studies [26].

The limitation of the current study includes; the small sample size as this type of stricture is infrequent and its retrospective nature. It is important to conduct a prospective or cohort study including a larger number of patients with clear inclusion and exclusion criteria to state clear indications and outcomes for the described technique.

\section{Conclusion}

Given the low number of patients and according to type of study (retrospective), the authors cannot affirm that "augmented anastomotic urethroplasty using ventral onlay pedicled skin flap" is an effective treatment. Prospective studies with larger sample size are needed.

\section{Abbreviations \\ AAU: Augmented anastomotic urethroplasty; SHIM: Sexual health inventory for men; Q-max: The maximum flow rate. \\ Authors' contributions \\ AE designed, analyzed the data, and revised the manuscript. AR designed the study, analyzed the data, and revised the manuscript. MSK designed the study, analyzed the data, and wrote the manuscript. All authors have read and approved the manuscript.}

\section{Availability of data and materials}

The datasets used and/or analyzed during the current study are available from the corresponding author on reasonable request.

\section{Ethics approval and consent to participate}

The study was approved by the ethics committee of Sohag University, Faculty of medicine with approval number REC/09/012020. Being retrospective analysis of the database, no written informed consent needed from patients 
prior to publications. Patients' clinical data were reviewed and analyzed anonymously without breaking patient's confidentiality.

\section{Competing interests}

The authors declare that they have no competing interests.

\section{Author details}

${ }^{1}$ Department of Urology, Ain Shams University Hospital, Cairo, Egypt.

${ }^{2}$ Department of Urology, Sohag University Hospital, Sohag, Egypt.

Received: 9 November 2020 Accepted: 1 February 2021

Published online: 17 February 2021

\section{References}

1. Hampson LA, McAninch JW, Breyer BN (2014) Male urethral strictures and their management. Nat Rev Urol 11(1):43-50

2. Mundy AR, Andrich DE (2011) Urethral strictures. BJU Int 107(1):6-26

3. Fenton AS et al (2005) Anterior urethral strictures: etiology and characteristics. Urology 65(6):1055-1058

4. Tritschler S et al (2013) Urethral stricture: etiology, investigation and treatments. Dtsch Arztebl Int 110(13):220-226

5. Gamal WM et al (2011) Penile fracture: long-term results of surgical and conservative management. J Trauma 71(2):491-493

6. El-Kassaby AW et al (2008) One-stage repair of long bulbar urethral strictures using augmented Russell dorsal strip anastomosis: outcome of 234 cases. Eur Urol 53(2):420-424

7. El-Kassaby AA, El-Zayat T (2007) 465 one-stage repair of long bulbar urethral strictures using augmented Russell dorsal strip anastomosis: Outcome of 234 cases. Eur Urol Suppl 6(2):139

8. Asopa HS et al (2001) Dorsal free graft urethroplasty for urethral stricture by ventral sagittal urethrotomy approach. Urology 58(5):657-659

9. Barbagli G et al (1996) A one-stage dorsal free-graft urethroplasty for bulbar urethral strictures. Br J Urol 78(6):929-932

10. Singh SK, Agrawal SK, Mavuduru RS (2011) Management of the stricture of fossa navicularis and pendulous urethral strictures. Indian J Urol 27(3):371-377

11. Barbagli $G$ et al (2014) Long-term followup and deterioration rate of anterior substitution urethroplasty. J Urol 192(3):808-813

12. Guralnick ML, Webster GD (2001) The augmented anastomotic urethroplasty: indications and outcome in 29 patients. J Urol 165(5):1496-1501
13. Abouassaly R, Angermeier KW (2017) Augmented anastomotic urethroplasty. J Urol 177(6):2211-2215

14. Rosen RC et al (1999) Development and evaluation of an abridged, 5 -item version of the International Index of Erectile Function (IIEF-5) as a diagnostic tool for erectile dysfunction. Int J Impot Res 11(6):319-326

15. Orandi A (1972) One-stage urethroplasty: 4-year followup. J Urol 107(6):977-980

16. Barbagli G et al (2016) Dorsal onlay graft bulbar urethroplasty using buccal mucosa. Afr J Urol 22(1):5-10

17. Kelami A (1983) Classification of congenital and acquired penile deviation. Urol Int 38(4):229-233

18. Ekeke ON, Amusan OE (2017) Clinical presentation and treatment of urethral stricture: experience from a tertiary hospital in Port Harcourt, Nigeria. Afr J Urol 23(1):72-77

19. Stein DM et al (2013) A geographic analysis of male urethral stricture aetiology and location. BJU Int 112(6):830-834

20. Hoy NY, Kinnaird A, Rourke KF (2013) Expanded use of a dorsal onlay augmented anastomotic urethroplasty with buccal mucosa for long segment bulbar urethral strictures: analysis of outcomes and complications. Urology 81(6):1357-1361

21. Hoy NY, Kinnaird A, Rourke KF (2013) Expanded use of a dorsal onlay augmented anastomotic urethroplasty with buccal mucosa for long segment bulbar urethral strictures: analysis of outcomes and complications (Urology 2013;81:1357-1361). Urology 81(6):1357-1361

22. Barbagli G, Palminteri E, Rizzo M (1998) Dorsal onlay graft urethroplasty using penile skin or buccal mucosa in adult bulbourethral strictures. J Urol 160(4):1307-1309

23. Barbagli G et al (2001) Long-term outcome of urethroplasty after failed urethrotomy versus primary repair. J Urol 165(6 Pt 1):1918-1919

24. Barbagli G, Morgia G, Lazzeri M (2008) Dorsal onlay skin graft bulbar urethroplasty: long-term follow-up. Eur Urol 53(3):628-634

25. Barbagli G et al (2005) Bulbar urethroplasty using buccal mucosa grafts placed on the ventral, dorsal or lateral surface of the urethra: are results affected by the surgical technique? J Urol 174(3):955-958

26. Reyad AM et al (2018) Dorsal versus ventral strip augmented anastomotic bulbar urethroplasty: retrospective study. Int Urol Nephrol 50(7):1257-1261

\section{Publisher's Note}

Springer Nature remains neutral with regard to jurisdictional claims in published maps and institutional affiliations.

\section{Submit your manuscript to a SpringerOpen ${ }^{\odot}$ journal and benefit from:}

- Convenient online submission

- Rigorous peer review

- Open access: articles freely available online

- High visibility within the field

- Retaining the copyright to your article

Submit your next manuscript at $\boldsymbol{\nabla}$ springeropen.com 